\title{
Diagnosis and treatment of obstructive sleep apnea in adults
}

\author{
Cheryl R. Laratta MD, Najib T. Ayas MD MPH, Marcus Povitz MD MSc, Sachin R. Pendharkar MD MSc
}

Cite as: CMAJ 2017 December 4;189:E1481-8. doi: 10.1503/cmaj.170296

CMAJ Podcasts: author interview at https://soundcloud.com/cmajpodcasts/170296-view

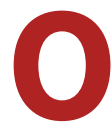

bstructive sleep apnea (OSA) is characterized by recurring episodes of cessation (apnea) or reduction (hypopnea) in airflow during sleep caused by obstruction of the upper airway. In recent population-based studies, the estimated prevalence of moderate to severe sleep-disordered breathing ranges from $3 \%$ to nearly $50 \%$ depending on age group and sex. ${ }^{1,2}$ A survey conducted by the Public Health Agency of Canada in 2009 found that $26 \%$ of Canadian adults reported symptoms and risk factors that are associated with a high risk of OSA ${ }^{3}$ however, prevalence data in Canada are limited by the absence of studies using objective sleep testing. Obstructive sleep apnea may be underdiagnosed; only $3 \%$ of Canadians aged 18 years or older reported a formal diagnosis despite high rates of symptom reporting; ${ }^{3}$ yet, high-quality prospective studies have shown clear benefit of treatment for patients with sleepiness, cognitive or psychological dysfunction, or poor quality of life owing to obstructive sleep apnea. ${ }^{4-6}$ Large population-based studies have shown that untreated moderate or severe OSA is associated with serious complications. ${ }^{7-9}$

We review signs, symptoms and morbidity associated with OSA, along with diagnostic options, treatments and considerations for long-term follow-up, based on evidence and recommendations from clinical guidelines, systematic reviews and primary studies (Box 1).

\section{Box 1: Evidence used in this review}

We conducted a structured literature search of MEDLINE and the Cochrane Database of Systematic Reviews for "obstructive sleep apnea" or "sleep apnea," in addition to targeted searches on PubMed. We excluded other forms of sleep disordered breathing. We limited our search to human studies that involved adults and that were published in the previous five years and written in English; however, we included several key papers that were published more than five years ago that substantially contributed to the field. We found 2921 articles, which were screened for relevance based on a review of titles and abstracts. Studies were selected for inclusion based upon the quality of evidence and relevance to the clinical questions discussed in this review.

\section{KEY POINTS}

- Obstructive sleep apnea (OSA) is likely underdiagnosed in Canada; however, lack of appropriate treatment puts many at risk of poor quality of life, comorbidity, motor vehicle crashes and increased health care utilization.

- Obstructive sleep apnea should be considered in symptomatic patients with suggestive craniofacial features or comorbidities, even in the absence of classic risk factors such as older age, male sex or obesity.

- Polysomnography is the gold standard for diagnosis; however, home sleep apnea testing may be used to confirm the diagnosis in symptomatic patients with a high pretest probability of OSA and without clinically important cardiopulmonary comorbidity.

- Good evidence supports treatment of OSA with targeted therapies including continuous positive airway pressure or oral appliances, as well as promotion of weight loss and moderate exercise for those who are overweight (alternative treatments may be tried for those who do not tolerate usual therapies).

\section{What signs, symptoms and risk factors should prompt consideration of obstructive sleep apnea?}

About $25 \%$ of patients with OSA report daytime sleepiness; a greater proportion report unrefreshing sleep or fatigue. ${ }^{10}$ Other symptoms include frequent nocturnal waking due to choking or gasping, nocturia, morning headaches, poor concentration, irritability and erectile dysfunction. ${ }^{11-13}$ Bed partners may report snoring or witnessed apneas. Atypical symptoms, which are more frequently reported by women, include insomnia, impaired memory, mood disturbance, reflux and nocturnal enuresis. ${ }^{14}$ However, the correlation of symptoms with disease severity is poor, ${ }^{15}$ which is why it is important for physicians to be alert to milder symptoms. There are many underlying risk factors, predisposing conditions and associated comorbidities for OSA; they are summarized in Appendix 1, available at www.cmaj.ca/ lookup/suppl/doi:10.1503/cmaj.170296/-/DC1. 
Features on physical examination that are associated with OSA include signs of central obesity (e.g., increased waist circumference, increased neck circumference), nasal septal deviation or turbinate hypertrophy, crowding of the posterior oropharynx as estimated by the Mallampati or Friedman score, or retrognathia. ${ }^{16-18}$ Oropharyngeal crowding may be caused by tonsillar enlargement, soft palate elongation, macroglossia or changes in dental occlusion. ${ }^{18}$ The pathophysiologic mechanisms predisposing to OSA are complex and overlapping; ${ }^{19}$ thus, neither history nor physical examination is sufficiently accurate to exclude the diagnosis of OSA. However, the features discussed above increase the pretest probability for OSA.

Various clinical prediction rules can assist in identifying patients with a high pretest probability for OSA; ${ }^{20}$ these include the Sleep Apnea Clinical Score, ${ }^{21}$ Berlin Questionnaire, ${ }^{22}$ cricomental distance, ${ }^{23}$ OSA50, ${ }^{24}$ STOP-Bang, ${ }^{25}$ elbow sign questionnaire ${ }^{26}$ and American Society of Anesthesiologists checklist. ${ }^{27}$ These tools have typically been validated in high-prevalence populations, which is an important consideration when implementing them in routine practice. Although the Epworth Sleepiness Scale ${ }^{28}$ may not accurately identify patients with OSA, ${ }^{20}$ it is a useful tool for evaluating subjective sleepiness and treatment response.

\section{Why is making a diagnosis of obstructive sleep apnea important?}

There is limited evidence to support adverse health consequences of mild OSA, but associations between untreated moderate or severe OSA and several complications have been shown in several large population studies (definitions available in Box 2). Severe OSA confers a 2.6 times increased risk of incident myocardial infarction, coronary revascularization, congestive heart failure or cardiovascular death after controlling for confounders such as body mass index. ${ }^{30}$ Risk of ischemic stroke is increased in patients with untreated OSA, particularly in men with an apnea-hypopnea index (AHI) of more than 19 events per hour or women with an $\mathrm{AHI}$ of more than 25 events per hour. ${ }^{31}$ Other important cardiometabolic associations include atrial fibrillation, resistant hypertension and insulin resistance. ${ }^{32,33}$ Although recurrent, intermittent hypoxemia may be a better predictor of cardiovascular risk than $\mathrm{AHI},{ }^{34,35}$ lack of improvement in hypertension with nocturnal oxygen therapy suggests that the underlying mechanism is more complex than hypoxemia alone. ${ }^{36}$

Some retrospective cohort studies have shown other diseases that are associated with OSA. Patients with concomitant OSA and chronic obstructive pulmonary disease have an increased risk of a severe exacerbation, leading to admission to hospital and increased mortality. ${ }^{37,38}$ Patients with OSA have two- to three times the risk of postoperative cardiopulmonary complications compared with patients without OSA. ${ }^{39,40}$ Maternal and fetal complications are increased in the presence of OSA (e.g., preeclampsia, gestational hypertension, preterm delivery, low birth weight). ${ }^{41,42}$ Obstructive sleep apnea is also associated with a two times increased risk of a motor vehicle crash, ${ }^{43}$ a complication with a high financial and health cost. ${ }^{4}$ Furthermore, untreated
OSA is associated with reduced work productivity and an increased risk of occupational injury. ${ }^{44,45}$ Treatment of OSA may mitigate many of these risks and is cost-effective. ${ }^{4,46,47}$

\section{How should obstructive sleep apnea be diagnosed?}

By consensus, the International Classification of Sleep Disorders defines OSA as the presence of symptoms or certain comorbidities associated with five or more predominantly obstructive respiratory events per hour or by 15 or more predominantly obstructive respiratory events per hour in asymptomatic patients (Box 2). ${ }^{29}$ The number of obstructive respiratory events is quantified by the $\mathrm{AHI}$, respiratory disturbance index or respiratory event index as outlined in Box 2.

According to recent US Preventive Services Task Force guidance on screening for OSA, there is no clear evidence to support population screening of asymptomatic individuals at low risk of OSA using sleep diagnostic testing. ${ }^{48}$

\section{Box 2: Diagnosing obstructive sleep apnea}

$A$ and $B$, or C satisfy the criteria for a diagnosis of obstructive sleep apnea (OSA). ${ }^{29}$

A. The presence of one or more of the following:

- The patient reports sleepiness, nonrestorative sleep, fatigue or insomnia symptoms.

- The patient wakes with breath holding, gasping or choking.

- The bed partner or other observer reports habitual snoring, breathing interruptions or both during the patient's sleep.

- A diagnosis of hypertension, a mood disorder, cognitive dysfunction, coronary artery disease, stroke, congestive heart failure, atrial fibrillation or type 2 diabetes mellitus in the patient.

B. Polysomnography or home sleep apnea testing shows:

- Five or more predominantly obstructive respiratory events per hour of sleep during polysomnography or per hour of monitoring during home sleep apnea testing.

\section{Polysomnography or home sleep apnea testing shows:}

- Fifteen or more predominantly obstructive respiratory events per hour of sleep during polysomnography or per hour of monitoring during home sleep apnea testing.

\section{Severity of OSA: ${ }^{20}$}

Mild OSA: $A H I \geq$ five events per hour

Moderate OSA: $A H I \geq 15$ events per hour

Severe OSA: AHI $\geq 30$ events per hour

\section{Definitions of terms quantifying $O S A^{8}$}

- Apnoea-hypopnea index (AHI): no. of apneas and hypopneas per hour of total sleep time

- Respiratory disturbance index (RDI): AHI with the addition of respiratory effort-related arousals per hour of sleep during polysomnography

- Respiratory event index (REI): no. of apneas and hypopneas per hour of total recording time on home monitoring devices for sleep apnea 


\section{Polysomnography}

The gold standard for diagnosis of OSA is attended polysomnography (level I study), which involves collection of seven or more data channels, including electroencephalogram and electrooculogram for sleep staging, electromyogram, electrocardiogram and respiratory channels. ${ }^{49}$ Home-based polysomnography (level II study) is not used commonly except for research. Sleep specialist assessment and polysomnography is particularly important when patients are at risk of central sleep apnea or hypoventilation; these conditions are suggested by the presence of neurologic disease, neuromuscular disease, congestive heart failure, severe lung disease, opioid use or obesity with a serum bicarbonate level of more than $27 \mathrm{mmol} / \mathrm{L} .^{50}$

Polysomnography is also indicated for the evaluation of suspected sleep disorders other than OSA or after nondiagnostic home sleep apnea testing among patients with a high pretest probability of OSA. ${ }^{20}$

\section{Home sleep apnea testing}

Several types of home sleep apnea testing are in clinical use. Level III sleep studies record a minimum of three channels of data while the patient sleeps at home. Level III studies usually monitor airflow, snoring, respiratory excursion, body position, heart rate and oxygen saturation, but some validated devices use surrogate measurements for these variables, such as tonometry or actigraphy, and the technology is constantly evolving. ${ }^{51}$ Level III studies do not record sleep; therefore, severity of OSA is estimated using the respiratory event index, which is the number of desaturation events per hour of total recording time.
The respiratory event index underestimates AHI because it measures time when the patient is not actually asleep ${ }^{52}$ and does not detect arousals from sleep.$^{20}$ In symptomatic patients with a moderate-to-high pretest probability of OSA and no substantial cardiopulmonary comorbidity, level III studies are adequate for the diagnosis of OSA (Table 1). ${ }^{53,54}$ As many as $17 \%$ of home sleep apnea tests are false negatives ${ }^{55}$ and up to $18 \%$ have technical failures. ${ }^{56}$ Therefore, if results for home sleep apnea testing are negative in a patient for whom there is a high index of suspicion, physicians should seek testing using polysomnography. Level III studies may also be useful when immobility, safety or illness preclude attendance for polysomnography and for confirmation of treatment efficacy. ${ }^{20}$

Level IV studies record one to two channels of data. One channel is oximetry, whereas the second channel may record snoring, airflow or heart rate. A recent randomized controlled trial (RCT) showed that clinicians diagnosed OSA with lower confidence when oximetry was used compared with level III testing or polysomnography. ${ }^{57}$

\section{What are the benefits of different treatment options?}

Table 2 summarizes the effectiveness of three different treatments for patients with OSA: continuous positive airway pressure, oral appliance and maxillomandibular advancement.

\section{Continuous positive airway pressure}

Symptomatic patients with OSA should undergo a trial of treatment with continuous positive airway pressure..$^{4,9}$ Continuous positive airway pressure reduces $\mathrm{AHI}$ and sleepiness. ${ }^{4}$ Although

\section{Table 1: Different types of diagnostic sleep testing}

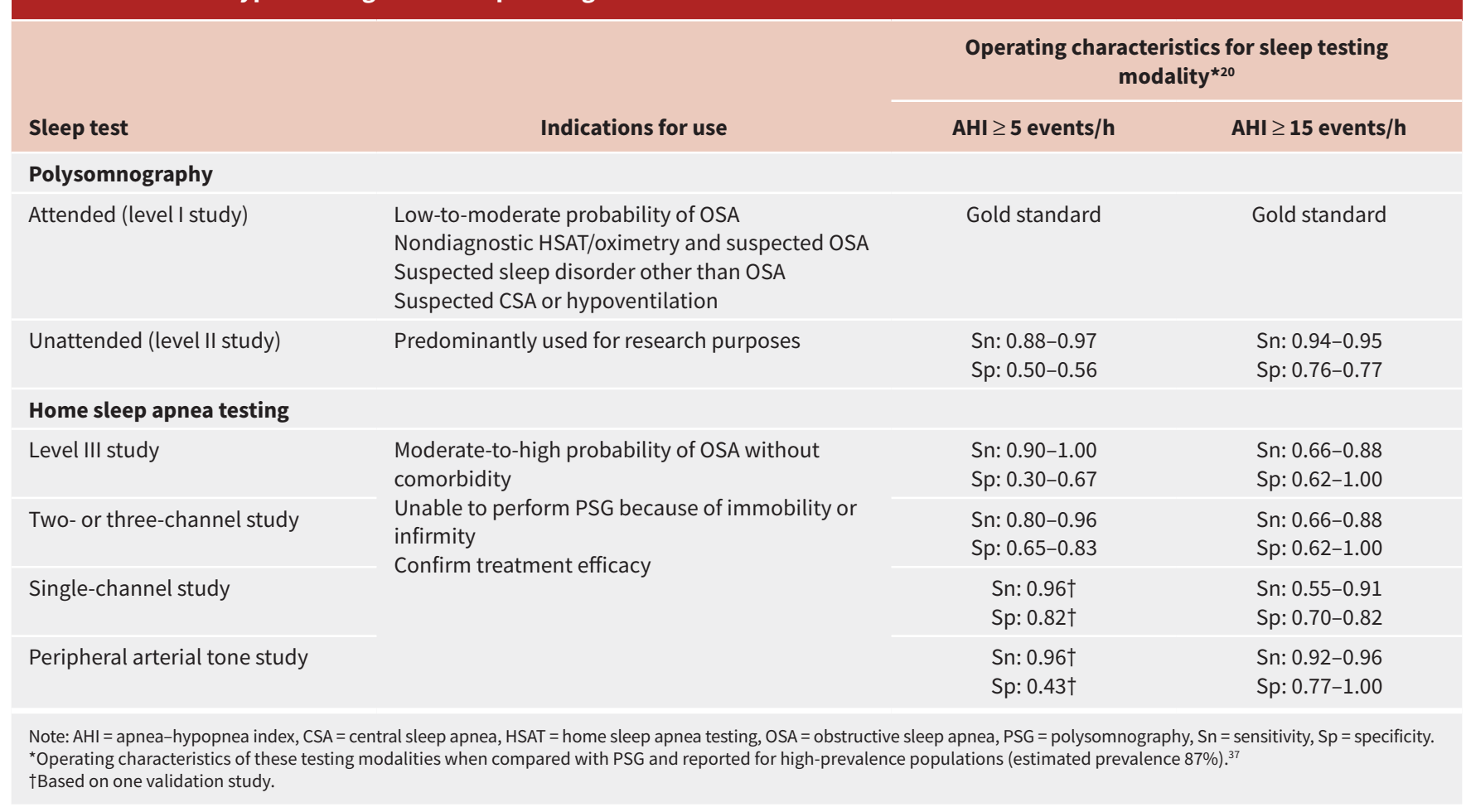


previous meta-analyses have not been definitive, the findings of some recent well-designed RCTs support that the use of continuous positive airway pressure improves quality of life. ${ }^{4-6}$ There is ongoing research to establish the benefits of OSA treatment on associated morbidity. Randomized controlled trials have shown reductions in blood pressure $(-4.39$ to $-1.41 \mathrm{~mm} \mathrm{Hg}){ }^{4}$

Other health benefits of treatment using continuous positive airway pressure for OSA are less clear. For example, there is conflicting evidence on the effects of continuous positive airway pressure on glycemic control in patients with diabetes. ${ }^{4,58}$ It is currently unclear if treatment can prevent some of the fetal and maternal complications (e.g., preeclampsia) associated with OSA. ${ }^{59-61}$ A systematic review and meta-analysis showed that therapy using continuous positive airway pressure reduced the risk of motor vehicle crashes in patients with moderate to severe OSA. ${ }^{62}$

Although observational studies have suggested a decreased risk of cardiovascular events in patients with severe OSA who are adherent to treatment, ${ }^{63}$ two recent RCTs (Sleep Apnea Cardiovascular Endpoints [SAVE] and Randomized Intervention with CPAP in Coronary Artery Disease and Sleep Apnea [RICCADSA]) reported that there was no cardiovascular benefit of treatment using continuous positive airway pressure in patients with OSA who had preexisting cardiovascular disease and minimal sleepiness. ${ }^{6,64}$ An important limitation of both studies was that adherence to the use of continuous positive airway pressure was below accepted guidelines for adequate use (mean adherence of less than 4 hours per night). ${ }^{65}$ Analysis of the outcomes in patients who were adherent to continuous positive airway pres- sure identified a lower risk of the composite outcome of repeat coronary artery revascularization, myocardial infarction, stroke or cardiovascular mortality in the RICCADSA study and a lower risk of cerebral events or stroke in the SAVE study. The SAVE study excluded patients with substantial nocturnal hypoxemia (oxygen saturation of less than $80 \%$ for more than $10 \%$ of recording time) in whom continuous positive airway pressure therapy may have more potential for reducing cardiovascular events. Furthermore, patients were followed only for an average of 3.7 years, which may not have been long enough to see cardiovascular benefits of therapy. These studies have generated controversy regarding the benefit of treatment for cardiovascular disease prevention. In our view, patients with moderate to severe OSA (regardless of symptoms) should be offered therapy in light of health, quality of life and workplace productivity benefits shown in adherent patients consistent with the findings in RCTs. ${ }^{6,66}$ However, we do not suggest using continuous positive airway pressure primarily for secondary prevention of cardiovascular events in asymptomatic patients.

\section{Oral appliances}

Oral appliances are recommended ${ }^{9,67}$ for patients with mild to moderate OSA who are intolerant of continuous positive airway pressure or prefer not to use it. These are either mandibular advancement or tongue-retaining devices. Oral appliances improve sleepiness, although a systematic review also identified that oral appliances decrease $\mathrm{AHI}$ to a lesser extent than continuous positive airway pressure. ${ }^{4}$ Further research is needed to determine if use of oral appliances improves quality of life. ${ }^{4}$

Table 2: Benefits of treatment for obstructive sleep apnea, by disease severity

Impact of treatment

\begin{tabular}{|c|c|c|c|}
\hline Severity of OSA & CPAP & OA & MMA \\
\hline Mild $^{7}$ & $\begin{array}{l}\text { AHI: Decreases AHI } \\
\text { Symptoms: } \\
\text { Unclear impact on ESS } \\
\text { Unclear impact on QoL } \\
\text { Cardiovascular: } \\
\text { Unclear effect on BP } \\
\text { Unclear reduction in CV events } \\
\text { Cerebrovascular: } \\
\text { Unclear impact }\end{array}$ & $\begin{array}{l}\text { AHI: Decreases AHI } \\
\text { Symptoms: } \\
\text { Unclear impact on ESS } \\
\text { Unclear impact on QoL } \\
\text { Cardiovascular: } \\
\text { Unclear impact on BP } \\
\text { Unclear impact on CV events } \\
\text { Cerebrovascular: } \\
\text { Unclear impact }\end{array}$ & $\begin{array}{l}\text { AHI: Unclear impact } \\
\text { Symptoms: } \\
\text { Unclear impact } \\
\text { Cardiovascular: } \\
\text { Unclear impact on CV events } \\
\text { Cerebrovascular: } \\
\text { Unclear impact }\end{array}$ \\
\hline Moderate to severe ${ }^{4}$ & $\begin{array}{l}\text { AHI: Decreases AHI } \\
\text { Symptoms: } \\
\text { Reduces ESS } \\
\text { Improves QoL }{ }^{5,6} \\
\text { Cardiovascular: } \\
\text { Decreases BP } \\
\text { Improves responsiveness of atrial fibrillation to } \\
\text { treatment } \\
\text { Unclear impact on CV events } \\
\text { Cerebrovascular: } \\
\text { May decrease risk of stroke } \\
\text { May improve outcomes after stroke }\end{array}$ & $\begin{array}{l}\text { AHI: Decreases AHI } \\
\text { Symptoms: } \\
\text { Reduces ESS } \\
\text { Unclear impact on QoL } \\
\text { Cardiovascular: } \\
\text { Decreases BP } \\
\text { Unclear impact on CV events } \\
\text { Cerebrovascular: } \\
\text { Unclear impact }\end{array}$ & $\begin{array}{l}\text { AHI: Decreases AHI } \\
\text { Symptoms: } \\
\text { Reduces ESS } \\
\text { Unclear impact on QoL } \\
\text { Cardiovascular: } \\
\text { Decreases BP } \\
\text { Unclear impact on CV events } \\
\text { Cerebrovascular: } \\
\text { Unclear impact }\end{array}$ \\
\hline
\end{tabular}

Note: $\mathrm{AHI}=$ apnea-hypopnea index, $\mathrm{BP}=$ blood pressure, $\mathrm{CPAP}=$ continuous positive airway pressure, $\mathrm{CV}=$ cardiovascular, ESS $=$ Epworth Sleepiness Scale, $\mathrm{MMA}=$ maxillomandibular advancement, $\mathrm{OA}=$ oral appliance, $\mathrm{OSA}=$ obstructive sleep apnea, $\mathrm{QOL}=$ quality of life. 
Lower efficacy may be balanced by greater adherence to this form of treatment compared with continuous positive airway pressure ( $80 \%-90 \%$ v. $50 \%-70 \%)$; thus, in mild to moderate disease, overall treatment effectiveness may be similar to continuous positive airway pressure.,4,67-69 Like continuous positive airway pressure, oral appliances can improve blood pressure modestly. ${ }^{4}$ However, other cardiovascular benefits of therapy using oral appliances have not been established..$^{70}$

The 2015 update of the American Academy of Sleep Medicine and American Academy of Dental Sleep Medicine clinical practice guideline recommended that, for best effect, appliances should be custom fitted by a dentist with extensive experience or additional training in dental sleep medicine. ${ }^{67}$ After the oral appliance has been custom fitted and jaw protrusion has been optimized, a sleep test should be ordered to evaluate treatment efficacy. ${ }^{71}$

\section{Alternative treatments}

Alternative treatment options include nasal expiratory positive airway pressure valves, exercises to strengthen oropharyngeal muscles (myofunctional therapy) and hypoglossal nerve stimulation (not approved in Canada). ${ }^{72}$ Tonsillectomy and adenoidectomy may help when tonsillar enlargement encroaches on the upper airway, particularly in younger patients. ${ }^{73}$ Tracheostomy is highly effective, ${ }^{74}$ yet rarely necessary unless there is substantial comorbidity and other treatments are ineffective. ${ }^{75}$

Patients frequently ask about surgery for treatment of OSA. Maxillomandibular advancement, with or without genial tubercle advancement, is an invasive surgical procedure that may be an option for highly selected patients who are intolerant of other therapies. ${ }^{76}$ However, a retrospective case-control study found that $13.9 \%$ of patients had a major complication that required repeat admission or unplanned surgery after maxillomandibular advancement, and numerous minor complications can occur. ${ }^{77}$ Regular follow-up to assess for recurrence of OSA is recommended..$^{75}$ Laser-assisted uvuloplasty or uvulopalatopharyngoplasty are unreliable for reducing the $\mathrm{AHI}$ or improving patient outcomes, and are not recommended. ${ }^{75,78}$ Decision aids for patients are under development and may help match treatments to patient preferences. ${ }^{79}$

\section{What are the principles of ongoing management and follow-up?}

The Canadian Thoracic Society guideline for the diagnosis and treatment of sleep disordered breathing in adults recommended that patients with sleep disordered breathing should be counselled to avoid excessive alcohol and sedative use. ${ }^{9} \mathrm{~A}$ metaanalysis of the effects of exercise training on sleep apnea ${ }^{80}$ and a longitudinal prospective cohort study ${ }^{81}$ reported, respectively, that exercise of moderate intensity and weight loss of $10 \%$ of baseline weight in patients who are overweight or obese resulted in modest reductions in AHI. For patients with supinepredominant OSA, a systematic review and meta-analysis found that positional therapy may reduce $\mathrm{AHI}$ by up to 10 events per hour but may be limited by poor adherence; in addition, there was no clear evidence of improvements in sleepiness, total sleep time or functional outcomes of sleep..$^{82}$ When appropriate, patients who are obese may be referred for bariatric surgery; after sustained weight loss, repeat testing may be indicated to determine if OSA persists. ${ }^{83}$

A consensus position paper on driving safety recommends that all patients with OSA should be counselled about driving safety. ${ }^{84}$ The criteria for when to notify provincial and territorial ministries of transportation about a patient with OSA varies and is typically based on the physician's assessment of risk. The American Thoracic Society clinical practice guideline for noncommercial drivers classifies patients as being at high risk if there is a history of unintentional or inappropriate sleep during daily activities, with either a recent motor vehicle crash or near miss owing to sleepiness, fatigue or inattention. ${ }^{85}$ The Canadian Council of Motor Transport Administrators publishes medical standards for commercial drivers with OSA;86 these standards specify that individuals without excessive sleepiness and an $\mathrm{AHI}$ of less than 20 events per hour are eligible to hold a commercial licence without receiving treatment for OSA, whereas those who have had a motor vehicle crash associated with falling asleep or have reported excessive sleepiness while driving must be treated. The physician's recommendations regarding treatment of those with an $\mathrm{AHI}$ of more than 20 events per hour are considered when determining licensure eligibility. The Canadian Medical Association's driver's guide provides criteria for mandatory reporting of patients in safety-critical occupations, such as commercial drivers, or those with key navigation roles in aviation, the railway or at sea. ${ }^{87}$

\section{Supporting adherence to treatment}

Initiation and maintenance of therapy using continuous positive airway pressure requires technical support. Important concerns are discussed in Appendix 2, available at www.cmaj.ca/lookup/ suppl/doi:10.1503/cmaj.170296/-/DC1. Adherence to this therapy within the first few days is a strong predictor of long-term adherence. ${ }^{88}$

Adherence to treatment with oral appliances can be assessed by patient report. Although some devices have built-in technology to objectively measure adherence, ${ }^{89,90}$ this type of device is not encountered frequently outside of clinical trials. Compliance in the use of oral appliances is increased if there is a reduction in snoring. ${ }^{90}$ Important adverse effects of oral appliances include aggravation of temporomandibular joint dysfunction, teeth shift, pain, gingival problems, excessive salivation or dry mouth. ${ }^{67,71}$ Regular dental follow-up is important for all patients who are prescribed oral appliances.

\section{Addressing persistent symptoms after successful treatment for obstructive sleep apnea}

Residual daytime sleepiness despite effective treatment of OSA may occur. Causes include chronic sleep restriction, central sleep apnea that comes to light with therapy using continuous positive airway pressure, another sleep disorder (e.g., narcolepsy), chronic medical or psychiatric conditions (e.g., depression) or adverse effects owing to medications (e.g., sedatives, antihistamines, $\beta$-blockers). About $5 \%$ of patients have persistent sleepiness 
despite exclusion of these causes and may benefit from drugs to promote wakefulness. ${ }^{91}$

\section{Future perspectives and unanswered questions}

There is emerging interest in personalized approaches to the diagnosis and management of OSA. Individualized treatment approaches acknowledge the complex biological mechanisms underlying OSA and aim to tailor treatments to the patient's physiology. Pathophysiologic mechanisms of OSA under investigation include an anatomic predisposition to upper airway collapse; increased ventilatory control instability (loop gain); reduced arousal threshold; ineffective upper airway dilator muscles or hypoglossal nerve function; decreased lung tethering; and nocturnal rostral fluid shift. Furthermore, research is underway to identify biomarkers and genetic factors that might predict adverse outcomes associated with OSA.92,93

In parallel with the development of targeted therapies for OSA, it is important that attention be paid to the wide variations in the diagnosis and treatment of OSA within Canada. ${ }^{94}$ Research into the models of service delivery for OSA, including strategies to improve timely access to care, funding for OSA treatment and patient preference, will be important to improve the care of Canadians with sleep disordered breathing.

\section{References}

1. Peppard PE, Young T, Barnet JH, et al. Increased prevalence of sleep-disordered breathing in adults. Am J Epidemiol 2013;177:1006-14.

2. Heinzer R, Vat S, Marques-Vidal P, et al. Prevalence of sleep-disordered breathing in the general population: the HypnoLaus study. Lancet Respir Med 2015; 3:310-8.

3. What is the impact of sleep apnea on Canadians? Fast facts from the 2009 Canadian Community Health Survey - sleep apnea rapid response. Ottawa: Public Health Agency of Canada; 2010. Available: www.phac-aspc.gc.ca/ cd-mc/sleepapnea-apneesommeil/pdf/sleep-apnea.pdf (accessed 2017 Mar. 9).

4. Interventions for the treatment of obstructive sleep apnea in adults: a health technology assessment. Ottawa: Canadian Agency for Drugs and Technologies in Health; 2017.

5. Campos-Rodriguez F, Queipo-Corona C, Carmona-Bernal C, et al. Continuous positive airway pressure improves quality of life in women with obstructive sleep apnea. A randomized controlled trial. Am J Respir Crit Care Med 2016; 194:1286-94.

6. McEvoy RD, Antic NA, Heeley E, et al. CPAP for prevention of cardiovascular events in obstructive sleep apnea. N Engl J Med 2016;375:919-31.

7. Chowdhuri S, Quan SF, Almeida F, et al. An official American Thoracic Society research statement: impact of mild obstructive sleep apnea in adults. Am J Respir Crit Care Med 2016;193:e37-54.

8. Berry RB, Brooks R, Gamaldo CE, et al.; American Academy of Sleep Medicine. The AASM Manual for the Scoring of Sleep and Associated Events: rules, terminology and technical specifications, version 2.3. Darien (II): American Academy of Sleep Medicine; 2016.

9. Fleetham J, Ayas N, Bradley D, et al. Canadian Thoracic Society guidelines: diagnosis and treatment of sleep disordered breathing in adults. Can Respir J 2006;13:387-92.

10. Tkacova R, Dorkova Z. Clinical presentations of OSA in adults. Eur Respir Monogr 2010;50:86-103.

11. Liu L, Kang R, Zhao S, et al. Sexual dysfunction in patients with obstructive sleep apnea: a systematic review and meta-analysis. J Sex Med 2015;12: 1992-2003.
12. Ustun B, Westover MB, Rudin C, et al. Clinical prediction models for sleep apnea: the importance of medical history over symptoms. J Clin Sleep Med 2016;12:161-8.

13. Epstein LJ, Kristo D, Strollo PJ Jr, et al. Clinical guideline for the evaluation, management and long-term care of obstructive sleep apnea in adults. J Clin Sleep Med 2009;5:263-76.

14. Basoglu OK, Tasbakan MS. Gender differences in clinical and polysomnographic features of obstructive sleep apnea: a clinical study of 2827 patients. Sleep Breath 2017 Feb. 14 [Epub ahead of print]. doi: 10.1007/ s11325-017-1482-9.

15. Edwards BA, Eckert DJ, Jordan AS. Obstructive sleep apnoea pathogenesis from mild to severe: Is it all the same? Respirology 2017;22:33-42.

16. Myers KA, Mrkobrada M, Simel DL. Does this patient have obstructive sleep apnea? The rational clinical examination systematic review. JAMA 2013; 310:731-41.

17. Friedman M, Hamilton C, Samuelson CG, et al. Diagnostic value of the Friedman tongue position and Mallampati classification for obstructive sleep apnea: a meta-analysis. Otolaryngol Head Neck Surg 2013;148:540-7.

18. Zonato Al, Bittencourt LR, Martinho FL, et al. Association of systematic head and neck physical examination with severity of obstructive sleep apnea hypopnea syndrome. Laryngoscope 2003;113:973-80.

19. Subramani Y, Singh M, Wong J, et al. Understanding phenotypes of obstructive sleep apnea: applications in anesthesia, surgery, and perioperative medicine. Anesth Analg 2017;124:179-91.

20. Kapur VK, Auckley DH, Chowdhuri S, et al. Clinical practice guideline for diagnostic testing for adult obstructive sleep apnea: an American Academy of Sleep Medicine clinical practice guideline. J Clin Sleep Med 2017;13:479-504.

21. Flemons WW, Whitelaw WA, Brant R, et al. Likelihood ratios for a sleep apnea clinical prediction rule. Am J Respir Crit Care Med 1994;150:1279-85.

22. Netzer NC, Stoohs RA, Netzer CM, et al. Using the Berlin Questionnaire to identify patients at risk for the sleep apnea syndrome. Ann Intern Med 1999;131:485-91.

23. Tsai WH, Remmers JE, Brant $\mathrm{R}$, et al. A decision rule for diagnostic testing in obstructive sleep apnea. Am J Respir Crit Care Med 2003;167:1427-32.

24. Chai-Coetzer CL, Antic NA, Rowland LS, et al. A simplified model of screening questionnaire and home monitoring for obstructive sleep apnoea in primary care. Thorax 2011;66:213-9.

25. Chung F, Abdullah HR, Liao P. STOP-Bang questionnaire: a practical approach to screen for obstructive sleep apnea. Chest 2016;149:631-8.

26. Fenton ME, Heathcote $\mathrm{K}$, Bryce R, et al. The utility of the elbow sign in the diagnosis of OSA. Chest 2014;145:518-24.

27. Gross JB, Bachenberg KL, Benumof JL, et al.; American Society of Anesthesiologists Task Force on Perioperative Management. Practice guidelines for the perioperative management of patients with obstructive sleep apnea: a report by the American Society of Anesthesiologists Task Force on Perioperative Management of Patients with Obstructive Sleep Apnea. Anesthesiology 2006; 104:1081-93.

28. Johns MW. A new method for measuring daytime sleepiness: the Epworth Sleepiness Scale. Sleep 1991;14:540-5.

29. American Academy of Sleep Medicine. International classification of sleep disorders, 3rd ed. Darien (II): American Academy of Sleep Medicine; 2014.

30. Hla KM, Young T, Hagen EW, et al. Coronary heart disease incidence in sleep disordered breathing: the Wisconsin sleep cohort study. Sleep 2015;38:677-84.

31. Redline S, Yenokyan G, Gottlieb DJ, et al. Obstructive sleep apnea-hypopnea and incident stroke. Am J Respir Crit Care Med 2010;182:269-77.

32. Jullian-Desayes I, Joyeux-Faure M, Tamisier R, et al. Impact of obstructive sleep apnea treatment by continuous positive airway pressure on cardiometabolic biomarkers: a systematic review from sham CPAP randomized controlled trials. Sleep Med Rev 2015;21:23-38.

33. Digby GC, Baranchuk A. Sleep apnea and atrial fibrillation; 2012 update. Curr Cardiol Rev 2012;8:265-72.

34. Kendzerska T, Leung RS, Gershon AS, et al. The interaction of obesity and nocturnal hypoxemia on cardiovascular consequences in adults with suspected obstructive sleep apnea. A historical observational study. Ann Am Thorac Soc 2016;13:2234-41.

35. Dewan NA, Nieto FJ, Somers VK. Intermittent hypoxemia and OSA: implications for comorbidities. Chest 2015;147:266-74. 
36. Gottlieb DJ, Punjabi NM, Mehra R, et al. CPAP versus oxygen in obstructive sleep apnea. N Engl J Med 2014;370:2276-85.

37. Marin JM, Soriano JB, Carrizo SJ, et al. Outcomes in patients with chronic obstructive pulmonary disease and obstructive sleep apnea. Am J Respir Crit Care Med 2010;182:325-31.

38. Stanchina ML, Welicky LM, Donat W, et al. Impact of CPAP use and age on mortality in patients with combined COPD and obstructive sleep apnea: the overlap syndrome. J Clin Sleep Med 2013;9:767-72.

39. Chung F, Memtsoudis SG, Ramachandran SK, et al. Society of Anesthesia and Sleep Medicine guidelines on preoperative screening and assessment of adult patients with obstructive sleep apnea. Anesth Analg 2016;123:452-73.

40. Kaw R, Chung F, Pasupuleti V, et al. Meta-analysis of the association between obstructive sleep apnoea and postoperative outcome. Br J Anaesth 2012; 109:897-906

41. Chen YH, Kang JH, Lin CC, et al. Obstructive sleep apnea and the risk of adverse pregnancy outcomes. Am J Obstet Gynecol 2012;206:136.e1-5.

42. Spence DL, Allen RC, Lutgendorf MA, et al. Association of obstructive sleep apnea with adverse pregnancy-related outcomes in military hospitals. Eur J Obstet Gynecol Reprod Biol 2017;210:166-72.

43. Tregear S, Reston J, Schoelles K, et al. Obstructive sleep apnea and risk of motor vehicle crash: systematic review and meta-analysis. J Clin Sleep Med 2009;5:573-81.

44. Hirsch Allen AJ, Park JE, Daniele PR, et al. Obstructive sleep apnoea and frequency of occupational injury. Thorax 2016;71:664-6.

45. Hirsch Allen AJM, Bansback N, Ayas NT. The effect of OSA on work disability and work-related injuries. Chest 2015;147:1422-8.

46. AlGhanim N, Comondore VR, Fleetham J, et al. The economic impact of obstructive sleep apnea. Lung 2008;186:7-12.

47. Povitz M, Tsai WH, Pendharkar SR, et al. Healthcare use in individuals with obesity and chronic hypoxemia treated for sleep disordered breathing. J Clin Sleep Med 2016;12:543-8.

48. Bibbins-Domingo K, Grossman DC, Curry SJ, et al. Screening for obstructive sleep apnea in adults: US Preventive Services Task Force recommendation statement. JAMA 2017;317:407-14.

49. Fleetham J, Ayas N, Bradley D, et al. Canadian Thoracic Society 2011 guideline update: diagnosis and treatment of sleep disordered breathing. Can Respir J 2011;18:25-47.

50. Randerath W, Verbraecken J, Andreas S, et al. Definition, discrimination, diagnosis and treatment of central breathing disturbances during sleep. Eur Respir J 2017;49: pii: 1600959.

51. El Shayeb M, Topfer L-A, Stafinski T, et al. Diagnostic accuracy of level 3 portable sleep tests versus level 1 polysomnography for sleep-disordered breathing: a systematic review and meta-analysis. CMAJ 2014;186:E25-51.

52. Bianchi MT, Goparaju B. Potential underestimation of sleep apnea severity by At-Home Kits: rescoring in-laboratory polysomnography without sleep staging. J Clin Sleep Med 2017;13:551-5.

53. Blackman A, McGregor C, Dales R, et al. Canadian Sleep Society/Canadian Thoracic Society position paper on the use of portable monitoring for the diagnosis of obstructive sleep apnea/hypopnea in adults. Can Respir J 2010;17:229-32.

54. Mulgrew AT, Fox N, Ayas NT, et al. Diagnosis and initial management of obstructive sleep apnea without polysomnography: a randomized validation study. Ann Intern Med 2007;146:157-66.

55. Collop NA, Anderson WM, Boehlecke B, et al. Clinical guidelines for the use of unattended portable monitors in the diagnosis of obstructive sleep apnea in adult patients. Portable Monitoring Task Force of the American Academy of Sleep Medicine. J Clin Sleep Med 2007;3:737-47.

56. Rosen CL, Auckley D, Benca R, et al. A multisite randomized trial of portable sleep studies and positive airway pressure autotitration versus laboratorybased polysomnography for the diagnosis and treatment of obstructive sleep apnea: the HomePAP study. Sleep 2012;35:757-67.

57. Chai-Coetzer CL, Antic NA, Hamilton GS, et al. Physician decision-making and clinical outcomes with laboratory polysomnography or limited-channel sleep studies for obstructive sleep apnea: a randomized trial. Ann Intern Med 2017;166:332-40.

58. Salord N, Fortuna AM, Monasterio C, et al. A Randomized controlled trial of continuous positive airway pressure on glucose tolerance in obese patients with obstructive sleep apnea. Sleep 2016;39:35-41.
59. Guilleminault C, Palombini L, Poyares D, et al. Pre-eclampsia and nasal CPAP: part 1. Early intervention with nasal CPAP in pregnant women with risk-factors for pre-eclampsia: preliminary findings. Sleep Med 2007;9:9-14.

60. Poyares D, Guilleminault C, Hachul $\mathrm{H}$, et al. Pre-eclampsia and nasal CPAP: part 2. Hypertension during pregnancy, chronic snoring, and early nasal CPAP intervention. Sleep Med 2007;9:15-21.

61. Abdullah HR, Nagappa M, Siddiqui N, et al. Diagnosis and treatment of obstructive sleep apnea during pregnancy. Curr Opin Anaesthesiol 2016;29: 317-24.

62. Tregear S, Reston J, Schoelles K, et al. Continuous positive airway pressure reduces risk of motor vehicle crash among drivers with obstructive sleep apnea: systematic review and meta-analysis. Sleep 2010;33:1373-80.

63. Marin JM, Carrizo SJ, Vicente E, et al. Long-term cardiovascular outcomes in men with obstructive sleep apnoea-hypopnoea with or without treatment with continuous positive airway pressure: an observational study. Lancet 2005;365:1046-53.

64. Peker Y, Glantz H, Eulenburg C, et al. Effect of positive airway pressure on cardiovascular outcomes in coronary artery disease patients with nonsleepy obstructive sleep apnea. The RICCADSA randomized controlled trial. Am J Respir Crit Care Med 2016;194:613-20.

65. Schwab RJ, Badr SM, Epstein LJ, et al. An official American Thoracic Society statement: continuous positive airway pressure adherence tracking systems. The optimal monitoring strategies and outcome measures in adults. Am J Respir Crit Care Med 2013;188:613-20.

66. Craig SE, Kohler M, Nicoll D, et al. Continuous positive airway pressure improves sleepiness but not calculated vascular risk in patients with minimally symptomatic obstructive sleep apnoea: the MOSAIC randomised controlled trial. Thorax 2012;67:1090-6.

67. Ramar K, Dort LC, Katz SG, et al. Clinical practice guideline for the treatment of obstructive sleep apnea and snoring with oral appliance therapy: an update for 2015: an American Academy of Sleep Medicine and American Academy of Dental Sleep Medicine clinical practice guideline. J Clin Sleep Med 2015;11: 773-827.

68. Bachour P, Bachour A, Kauppi P, et al. Oral appliance in sleep apnea treatment: respiratory and clinical effects and long-term adherence. Sleep Breath 2016;20:805-12.

69. Salepci B, Caglayan B, Kiral N, et al. CPAP adherence of patients with obstructive sleep apnea. Respir Care 2013;58:1467-73.

70. Gagnadoux F, Pepin JL, Vielle B, et al. impact of mandibular advancement therapy on endothelial function in severe obstructive sleep apnea. Am J Respir Crit Care Med 2017;195:1244-52.

71. Gauthier L, Almeida F, Arcache P, et al. Position paper by Canadian dental sleep medicine professionals regarding the role of different health care professionals in managing obstructive sleep apnea and snoring with oral appliances. Can Respir J 2012;19:307-9.

72. Strollo PJ, Soose RJ, Maurer JT, et al. Upper-airway stimulation for obstructive sleep apnea. N Engl J Med 2014;370:139-49.

73. Camacho M, Li D, Kawai M, et al. Tonsillectomy for adult obstructive sleep apnea: a systematic review and meta-analysis. Laryngoscope 2016;126: 2176-86.

74. Camacho M, Certal V, Brietzke SE, et al. Tracheostomy as treatment for adult obstructive sleep apnea: a systematic review and meta-analysis. Laryngoscope 2014;124:803-11.

75. Aurora RN, Casey KR, Kristo D, et al. Practice parameters for the surgical modifications of the upper airway for obstructive sleep apnea in adults. Sleep 2010; 33:1408-13.

76. Zaghi S, Holty JE, Certal V, et al. Maxillomandibular advancement for treatment of obstructive sleep apnea: a meta-analysis. JAMA Otolaryngol Head Neck Surg 2016;142:58-66.

77. Passeri LA, Choi JG, Kaban LB, et al. Morbidity and mortality rates after maxillomandibular advancement for treatment of obstructive sleep apnea. J Oral Maxillofac Surg 2016;74:2033-43.

78. Camacho M, Nesbitt NB, Lambert E, et al. Laser assisted uvulopalatoplasty (LAUP) for obstructive sleep apnea: a systematic review and meta-analysis. Sleep 2017;40. doi: 10.1093/sleep/zsx004.

79. Trenaman L, Munro S, Almeida F, et al. Development of a patient decision aid prototype for adults with obstructive sleep apnea. Sleep Breath 2016; 20:653-61. 
80. Iftikhar IH, Kline CE, Youngstedt SD. Effects of exercise training on sleep apnea: a meta-analysis. Lung 2014;192:175-84.

81. Peppard PE, Young T, Palta M, et al. Longitudinal study of moderate weight change and sleep-disordered breathing. JAMA 2000;284:3015-21.

82. Barnes H, Edwards B, Joosten S, et al. Positional modification techniques for supine obstructive sleep apnea: a systematic review and meta-analysis. Sleep Med Rev 2016 Nov 18. pii: S1087-0792(16)30138-1 [Epub ahead of print]. doi: 10.1016/j.smrv.2016.11.004

83. Ashrafian H, Toma T, Rowland SP, et al. Bariatric surgery or non-surgical weight loss for obstructive sleep apnoea? A systematic review and comparison of meta-analyses. Obes Surg 2015;25:1239-50.

84. Ayas N, Skomro R, Blackman A, et al. Obstructive sleep apnea and driving: a Canadian Thoracic Society and Canadian Sleep Society position paper. Can Respir J 2014;21:114-23.

85. Strohl KP, Brown DB, Collop N, et al. An official American Thoracic Society Clinical Practice Guideline: sleep apnea, sleepiness, and driving risk in noncommercial drivers. An update of a 1994 statement. Am J Respir Crit Care Med 2013;187:1259-66.

86. CCMTA medical standards for drivers. Ottawa: Canadian Council of Motor Transport Administrators; 2006.

87. CMA driver's guide. Determining medical fitness to operate motor vehicles. 9th ed. Ottawa: The Canadian Medical Association; 2017.
88. Weaver TE, Grunstein RR. Adherence to continuous positive airway pressure therapy: the challenge to effective treatment. Proc Am Thorac Soc 2008; 5:173-8.

89. Vanderveken OM, Dieltjens M, Wouters K, et al. Objective measurement of compliance during oral appliance therapy for sleep-disordered breathing. Thorax 2013;68:91-6.

90. Dieltjens M, Verbruggen AE, Braem MJ, et al. Determinants of objective compliance during oral appliance therapy in patients with sleep-disordered breathing: a prospective clinical trial. JAMA Otolaryngol Head Neck Surg 2015;141:894-900.

91. Chapman JL, Vakulin A, Hedner J, et al. Modafinil/armodafinil in obstructive sleep apnoea: a systematic review and meta-analysis. Eur Respir J 2016; 47:1420-8.

92. Zinchuk AV, Gentry MJ, Concato J, et al. Phenotypes in obstructive sleep apnea: a definition, examples and evolution of approaches. Sleep Med Rev 2017;35:113-23.

93. Subramani Y, Singh M, Wong J, et al. Understanding phenotypes of obstructive sleep apnea: applications in anesthesia, surgery, and perioperative medicine. Anesth Analg 2017;124:179-91.

94. Fleetham J. Postal code diagnosis and treatment of sleep apnea. Can Respir J 2010;17:169.
Competing interests: Najib Ayas has received support from Bresotec outside of the submitted work. Sachin Pendharkar receives renumeration from VitalAire Canada for the interpretation of home sleep apnea tests and honoraria from RHS Canada for the provision of continuing education on obstructive sleep apnea. No other competing interests were declared.
Affiliations: Department of Medicine (Laratta, Ayas); Sleep Disorders Program (Laratta, Ayas), University of British Columbia, Vancouver, BC; Department of Medicine (Povitz); Department of Epidemiology and Biostatistics (Povitz), Schulich School of Medicine and Dentistry, Western University, London, Ont.; Department of Medicine (Pendharkar); Department of Community Health Sciences (Pendharkar), Cumming School of Medicine, University of Calgary, Calgary, Alta.
Contributors: All of the authors contributed subtantially to the conception and design of the work, revised it critically for important intellectual content, gave final approval of the version to be published and agreed to be accountable for all aspects of the work.

Funding: The authors received no external funding for this review.

This article has been peer reviewed.

Correspondence to: Sachin Pendharkar, sachin.pendharkar@ucalgary.ca 